\title{
Establishment and application of soil hydraulic erosion model based on GIS and USLE model
}

\author{
Guo Ke-xin ${ }^{1 *}$, Cao Ying-xian ${ }^{2}$ \\ ${ }^{1}$ School of Information Engineering, China University of Geosciences (Beijing), 100083, Beijing China \\ ${ }^{2}$ College of Land Science and Technology, China Agricultural University, Beijing 100083, China
}

\begin{abstract}
Soil erosion is the most common form of soil degradation, which is the main problem of soil environmental destruction worldwide. Based on the USLE and GIS remote sensing inversion and superposition analysis technology, this study simulated and calculated soil hydraulic erosion in Fangshan World Geological Park, China in 2011, 2012 and 2013, analyzed its spatial-temporal dynamic changes, and explored the key points of soil erosion control in the study area. The results show that (1) The main erosion occurred at $25^{\circ}-35^{\circ}$ steep slope and $400-800 \mathrm{~m}$ height, which accounted for more than $30 \%$ of the total soil erosion in all the three years. (2) The average erosion modulus and erosion amount in 2012 were significant higher than that in 2011 and 2013 at each slope grade, shown that the soil erosion of 2012 is influenced by natural disaster. With the increase of slope grade, the average modulus also increased.
\end{abstract}

\section{Introduction}

The USLE soil loss equation is the earliest and most influential model in empirical statistical models. It is widely used in the spatio-temporal changes of soil erosion ${ }^{[1]}$ and the assessment of regional soil erosion risks ${ }^{[2,3]}$. In this study, by modifying the universal soil loss equation USLE, combining GIS and remote sensing technology, the soil water erosion in China Fangshan World Geopark from 2011 to 2013 was simulated and calculated to verify the applicability of the USLE model, analyze its temporal and spatial dynamic characteristics, and explore key points of soil erosion prevention and control in the study area. The study can provide reference for the construction of the soil erosion monitoring system in this area, and provide rich experience support for the establishment and application of the model.

\section{Establishment of Soil Water Erosion Model Based on USLE}

\subsection{USLE}

The general soil loss equation is generally composed of six influencing factors including precipitation erosivity factors, soil erodibility factors, slope length factors, slope factors, vegetation cover and crop management factors, and soil and water conservation measure ${ }^{[1]}$. The basic form is as follows:

$$
A=R \times K \times L \times S \times C \times P
$$

Among them: A is the amount of soil loss per-unit area, the unit is: $\mathrm{t} /(\mathrm{hm} 2 \cdot \mathrm{h} \cdot \mathrm{a})($ or: $\mathrm{t} /(\mathrm{km} 2 \cdot \mathrm{h} \cdot \mathrm{a}))$.

\subsection{Calculation of soil erosion influencing factors}

The table for the meaning and calculation formula or search method of each soil erosion influencing factor show as follows(Table 1):

Table 1. Meaning and calculation formula or search method of each soil erosion influencing factor

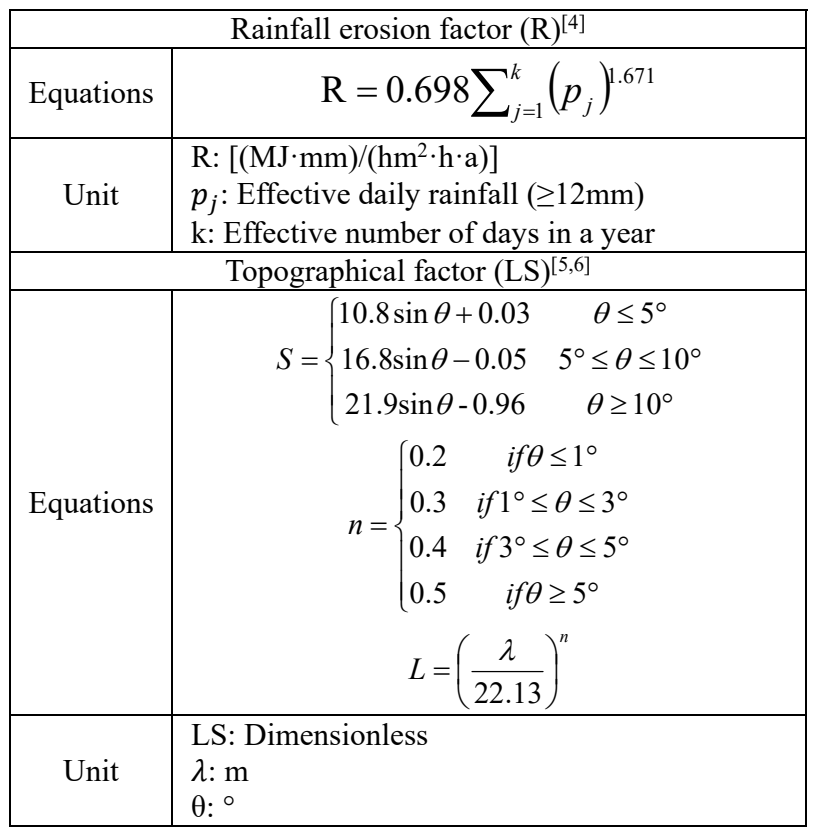

\footnotetext{
*Corresponding author's e-mail: 1004185211@cugb.edu.cn
} 


\begin{tabular}{|c|c|}
\hline \multicolumn{1}{|c|}{ Soil erodibility factor $(\mathrm{K})^{[7]}$} \\
$\quad \begin{array}{c}K_{n}=\alpha \times \beta \times \gamma \times \delta \\
\text { Equations }\end{array}$ \\
$\quad \beta=\left(\frac{\mathrm{SIL}}{\mathrm{CAL}+\mathrm{SIL}}\right)^{0.3}$
\end{tabular}

\section{Case study in Fangshan World Geological Park}

\subsection{Regional background}

Fangshan World Geopark is located at the junction of southwest Beijing and Hebei Province, with an elevation of $26 \mathrm{~m}-2161 \mathrm{~m}$, a length of $130.80 \mathrm{~km}$ from east to west, and a width of $75.09 \mathrm{~km}$ from north to south. The total area of the park is $1045 \mathrm{~km}^{2}$. The Fangshan World Geopark is located at the intersection of the Taihang Mountains and the Yanshan Mountains. Rainfall is the main reason of soil erosion, the ground is mostly not solidified. When the water flows down from high places, it is easy to form mountain torrents, leading to serious soil erosion.

\subsection{Data source and preprocessin}

The data used in this study include: daily precipitation data in 2011, 2012, and 2013, provided by the China Meteorological Data Sharing Network and the National Meteorological Information Center. The vegetation index data comes from the Resource and Environment Data Center of the Chinese Academy of Sciences, and the product is synthesized at $500 \mathrm{~m}$. The land use data comes from the Resource and Environment Science Data Center with a resolution of $1000 \mathrm{~m}$. The soil attribute data is provided by the soil data of 1:1 million provided by Nanjing Soil in the Second National Land Survey. Digital elevation model with a spatial resolution of $30 \mathrm{~m}$.

\subsection{Temporal and spatial distribution of soil erosion grade}

The soil erosion intensity grades of Fangshan World Geopark in each year are shown in Figure 1. Most areas of the study area are slightly eroded. The figure shows the key points of soil water erosion where lies at northern part of the Geopark. It can be seen that in 2012, when the extreme rainstorm occurred, the soil erosion is significant more serious than in 2011 and 2013.

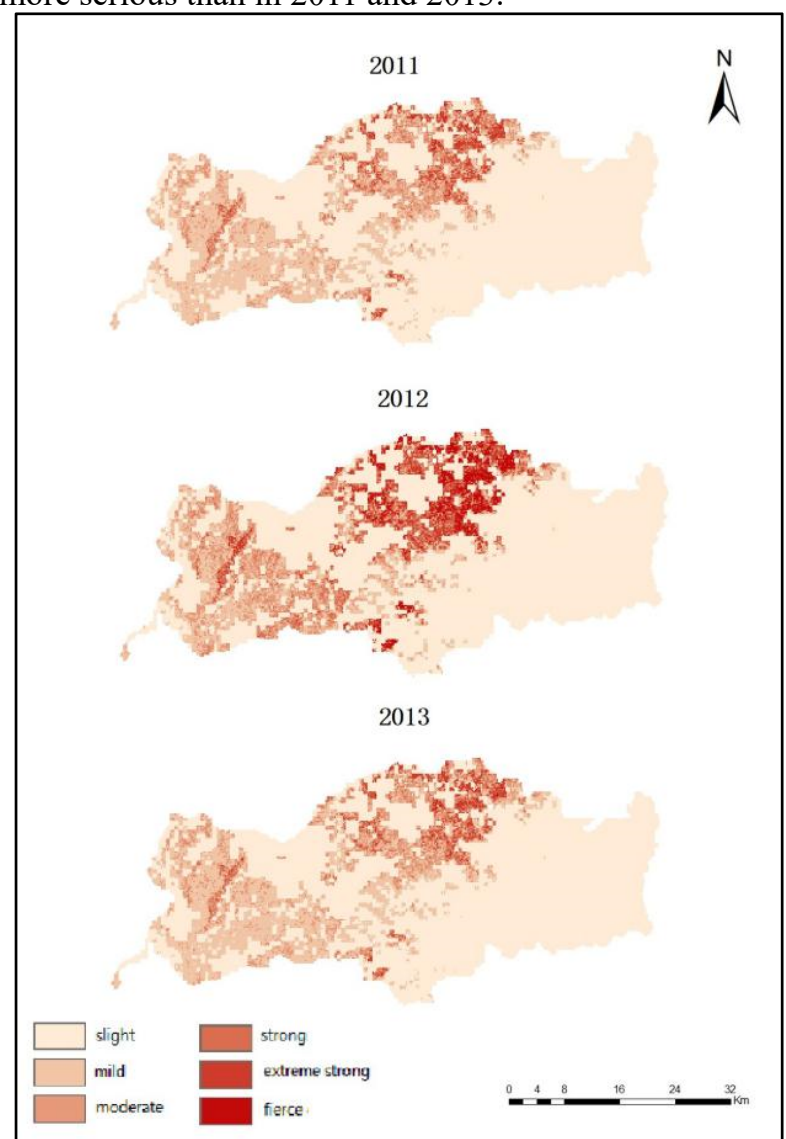

Figure 1. Classification of soil erosion intensity in Fangshan World Geopark,China

\subsection{Dynamic Analysis of Soil Water Erosion}

The soil erosion modulus and the amount of soil erosion are affected by various soil erosion factors, and soil erosion factors are closely related to various environmental factors ${ }^{[4]}$. On the basis of dividing the severely eroded area and the high-risk area, the key points of soil erosion under specific environmental conditions are identified through analysis. This study is based on slope, elevation, etc. to analyze. 


\subsubsection{Analysis of soil erosion intensity under each height zone}

According to the elevation range of the study area $(26 \mathrm{~m}-2161 \mathrm{~m})$, for the purpose of distinguishing the elevation gradient, the elevations involved in the Fangshan World Geopark are divided equally into five ranges $<400 \mathrm{~m}, 400 \mathrm{~m} \sim 800 \mathrm{~m}, 800 \mathrm{~m} \sim 1200 \mathrm{~m}$, and $>1200 \mathrm{~m}$. In terms of average erosion modulus, $400-800 \mathrm{~m}$ elevation has the highest erosion modulus and the largest amount of erosion. The average erosion modulus in the range of $<400 \mathrm{~m}$ elevation is second, and the average erosion modulus of $>1600 \mathrm{~m}$ elevation is among the five elevation zones. The smallest is mainly due to the vigorous vegetation growth in the study area, less man-made damage, better water and soil conservation, and significantly lower soil erosion modulus under this elevation zone.

From the perspective of inter-annual changes, the amount of erosion experienced a change that first increased and then decreased. In 2011, it was $1555.90 \times 104 \mathrm{t} / \mathrm{a}$, and reached a maximum of $200.43 \times 104 \mathrm{t} / \mathrm{a}$ in 2012 , while it was $961.75 \times 104 \mathrm{t} / \mathrm{a}$ in 2013. The average erosion modulus has dropped significantly, and the average erosion modulus has also shown a similar trend of first decline and then rise. Based on the research background, this is due to the impact of the extremely heavy rain in Beijing on the Fangshan District on July 21, 2012. The heavy rain caused a significant increase in soil hydraulic erosion. Both the erosion modulus and the amount of erosion decreased significantly in 2013. It can be considered that after the heavy rains in 2012, the country's restoration and protection measures for the ecological environment have taken effect, and the soil erosion of Fangshan World Geopark has improved overall.

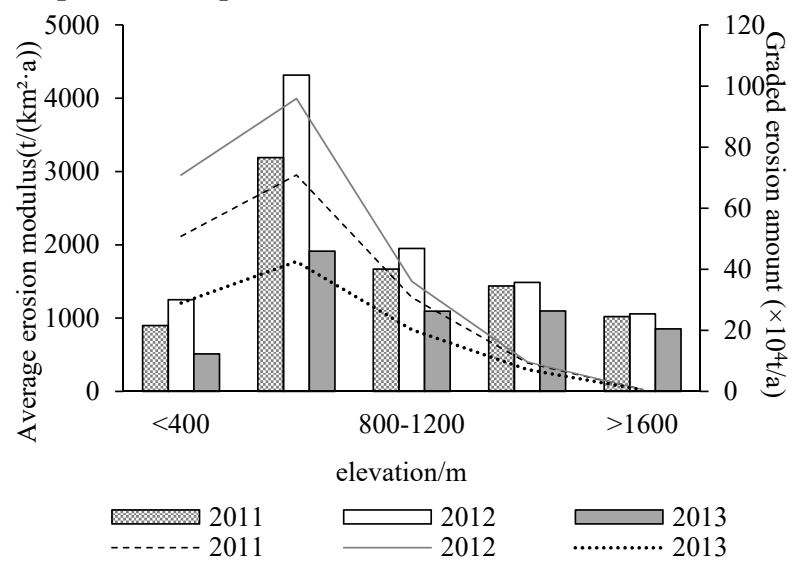

Figure 2. Characteristics of soil erosion in different evelation grades

\subsubsection{Analysis of the amount of soil erosion in each grade of slope zone}

According to the General Principles of Comprehensive Treatment Planning for Soil and Water Conservation $(\mathrm{GB} / \mathrm{T} 15772-2008)^{[12]}$, the surface slope is divided into six grades: $0^{\circ} \sim 5^{\circ}, 5^{\circ} \sim 8^{\circ}, 8^{\circ} \sim 15^{\circ}, \quad 15^{\circ} \sim 25^{\circ}, 25^{\circ} \sim 35^{\circ}$, and $>35^{\circ}$. Soil erosion characteristics of different slope zones (Figure 3).

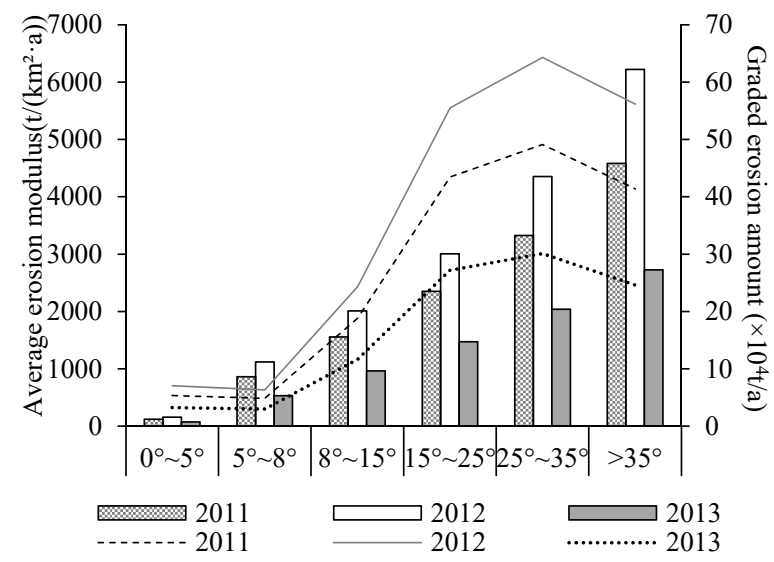

Figure 3. Characteristics of soil erosion in different slope grades

From the perspective of erosion modulus, basically the slope increases, and the erosion modulus also increases. In 2012, the average erosion modulus of extremely steep slopes reached $6219.616 \mathrm{t} /\left(\mathrm{km}^{2} \cdot \mathrm{a}\right)$. In terms of the amount of erosion, the main erosion occurs at the steep slope grade of $25^{\circ}-35^{\circ}$. The soil erosion of this grade accounts for more than $30 \%$ of the total erosion in three years. The grades of gentle slopes, steep slopes and extremely steep slopes are in each year. The distribution of erosion amount is relatively uniform, but extremely steep slope grades account for a large proportion, respectively, $25.40 \%$ in $2011,26.28 \%$ in 2012 , and $24.65 \%$ in 2013 . The proportion of erosion corresponding to the grades of micro-slope and gentle slope is low in each year, with micro-slope around 3.3\% and gentle slope around 3\%.

In terms of inter-annual variation, the average erosion modulus and erosion amount in 2012 under each slope grade are higher than those in 2011 and 2013. As the slope grade increases, the average modulus also increases, and the graded erosion amount It shows a trend of increasing first and then decreasing. The proportion of micro-slope is always small, but the total erosion amount also increased significantly in 2012 , from $5.337586 \times$ $104 \mathrm{t} / \mathrm{a}$ in 2011 to $7.055324 \times 104 \mathrm{t} / \mathrm{a}$. In general, all grades except for extremely steep slope grades are more evenly distributed. The distribution of soil erosion corresponding to each slope was severely eroded in 2012, and the soil and water conservation capacity was better in 2011 and 2013.

\section{Conclusion}

Refer to the soil erosion survey report issued by the Beijing Municipal Water and Soil Conservation Station, where water erosion is the main erosion method in Fangshan District. Among them, the slightly eroded area accounts for $69 \%$, and the slightly eroded area accounts for $22 \%$. The erosion level in a few areas is above moderate, which is similar to the conclusions of this study, indicating that the method of this study is feasible, the calculation results are generally reasonable, and have analytical value. 
(1) As far as the results of the graded analysis of erosion intensity are concerned, the proportion of slightly eroded area in each year is more than $65 \%$, the erosion modulus increases with the increase of erosion intensity, and the corresponding erosion area decreases.

(2) According to the classification of the height zone, the $400 \mathrm{~m}-800 \mathrm{~m}$ elevation zone is the main contributor to the amount of soil erosion. The average erosion modulus is $1914-4316 \mathrm{t} /(\mathrm{km} 2 \cdot \mathrm{a})$, and the total erosion amount is $42.83 \% \sim 45.01 \%$. Protecting the vegetation coverage in this elevation zone is of great significance to the further improvement of soil water erosion in the World Geopark.

(3) According to the grade of slope, the soil erosion modulus corresponding to each grade of slope increases as the grade increases. The grade of gentle slope $\left(8^{\circ}\right.$ $\sim 15^{\circ}$ ) occupies $14.14 \%$ of the total area, and the amount of erosion accounts for $30.10 \%$ to $30.13 \%$ of the total, becoming the main source of erosion. In general, the grades of gentle slopes and steep slopes are the key areas for soil erosion prevention and control in Fangshan World Geopark

\section{References}

1. Wischmeier W H. (1971) A soil erodibility nomograph for farmland and construction sites. Jouranl of Soil and Water Consercation, 26: 189-193.

2. Cai Q G, Liu J G. (2003) Evolution of Soil Erosion Models in China. PROGRESS IN GEOGRAPHY, 22: 242-250.
3. Xu B L, Lu H, Shao D G. (2014) Regional Soil Erosion Based on RS and GIS.Journal of Irrigation and Drainage, 33: 291-294.

4. Zhang WB, Fu J S. (2003) RAINFALL EROSIVITY ESTIMATION UNDER DIFFERENT RAINFALL AMOUNT. RESOURCES SCIENCE, 25: 35-41.

5. Liu B Y, Nearing M A, Risse L M. (2000) Slope gradient effects on soil loss for steep slopes. Soil \& Water Management \& Conservation, 64: 1759-1763.

6. Fu S H, Liu B Y, Zhou G Y, Sun Z X, Zhu X L. (2015) Calculation tool of topographic factors. Science of Soil and Water Conservation, 13: 105-110.

7. Zhang J C, Li H D, Lin J, Li Y J, Jiang J, Tao B X, Zhang D H. (2008) Spatial variability of soil erodibility (K-Factor) at a catchment scale in China. ACTA ECOLOGICA SINICA, 28: 2199-2206.

8. Zhu H, Tang T T, Cai Y R. (2015) Research Progress of Soil and Water Conservation Measure Factors in Soil Erosion Forecast Model. Technology Outlook, 0: 222-224.

9. Lin H L, Zheng S T, Wang X L. (2017) Soil erosion assessment based on the RUSLE model in the Three-Rivers Headwaters area, Qinghai-Tibetan Plateau, China. Acta Prataculturae Sinica, 26: 11-22.

10. Yuan K Q, Ni J P, Gong C M, Chen X Y. (2009) Research Progress of Soil Erosion Prediction and Evaluation Based on GIS. TECHNOLOGY OF SOIL AND WATER CONSERVATION, 0: 18-22. 